\title{
Mesleki Eğitime Yönelik Arttırılmış ve Sanal Gerçeklik Teknolojilerinin Tek Bir Uygulamada Birleştirilerek Karma Gerçeklik Uygulaması Geliştirilmesi ve Donanım Tasarlanması
}

\author{
${ }^{1}$ Muhammed Kofoğlu \\ ${ }^{1}$ Bursa Teknik Üniversitesi, Mühendislik ve Doğa Bilimleri Fakültesi, Bursa, Türkiye
}

\begin{abstract}
Özet
Endüstride bakım onarım, imalat, üretim planlama ve pazarlama gibi alanlarda arttıılmış (AG), sanal (SG) ve karma gerçeklik (XR) teknolojileri kullanılmaktadır. Bu teknolojiler gerçek dünya ile dijital dünya arasındaki geçişi sağlamaktadır. Birçok alanda başarı ile kullanılan bu teknolojiler eğitim ve öğretim alanlarında da temel matematik eğitiminden ileri mühendislik konularına kadar yardımcı ekipman olarak kullanılmaktadır. Araştırma kapsamında, endüstri ve eğitim alanları başta olmak üzere birçok alanda uygulama geliştirilen AG ve SG teknolojileri incelenmiş ve yöntemlerin kullanıcılara sunduğu faydalar ve teknolojilerin kısıtları araştırılmıştır. Araştırma sonucunda ortaya çıan rapor değerlendirilmiş ve ihtiyaç olduğu düşünülen sorunlara makul bir çözüm geliştirilmiştir. Burada, teknik ve mühendislik eğitimlerine yönelik hem arttırılmış hem de karma gerçeklik yöntemlerini tek bir uygulamada sunarak kullanıcıların tek bir uygulama ile her iki tekniğin faydalarından yararlanması amaçlanmıştır. Bu doğrultuda hem arttırılmış hem de karma gerçeklik tekniğini destekleyen uygulama geliştirilmiş ve uygulamayı kullanmayı sağlayan bir karma gerçeklik gözlüğü tasarlanmıştır.
\end{abstract}

Anahtar kelimeler: Arttırılmış gerçeklik, karma gerçeklik, mesleki eğitim

\begin{abstract}
Augmented, virtual and mixed reality technologies are used in the industry such as maintenance, manufacturing, production planning and marketing. These technologies provide the transition between the real world and the digital world. These technologies, which are used successfully in many fields, are also used as auxiliary equipment in education and training areas from basic mathematics education to advanced engineering subjects. Within the scope of this research, applications developed in many fields, especially in the fields of industry and education, were increased and virtual reality technologies were examined and the benefits of the methods to the users and the limitations of the technologies were investigated. The report resulting from the research was evaluated and a reasonable solution was developed for the problems thought to be needed. Here, it is aimed to provide both augmented and mixed reality methods for technical and engineering education in a single application so that the users can benefit from both techniques with a single application. In this respect, both an augmented and an application that supports mixed reality technique has been developed and a mixed reality glasses designed to use the application has been designed.
\end{abstract}

Key words: Augmented reality, mixed reality, vocational training

*İletişim Yazarı: Adres: Mühendislik ve Doğa Fakültesi, Makine Mühendisliği Bölümü Bursa Teknik Üniversitesi, 16000, Bursa TÜRKIYY. E-mail adres: muhammedkofoglu@gmail.com, Tel: +905453329101 


\section{Giriş}

AG ve SG teknolojileri gerçek dünya ile dijital dünya arasındaki geçişi sağlamaktadır. Bu nedenle $A G$ ve $S G$ 'in her geçen gün yeni bir uygulaması hatta uygulama alanı ortaya çıkmaktadır. Çünkü teknolojinin evrimine yetişmek ve geleceği şekillendirmek için bu teknolojilerin hayatın her aşamasına uyarlanması gerekmektedir.

Sanal nesneleri gerçek hayata dâhil ederek kullanıcıları eğitmek, öğretmek veya bir şeylere yönlendirmek yöntemin temel amacıdır. Mevcut olan birçok çalışmada da bu amaçla kullanılmaktadır. Başta eğitim olmak üzere sağlık, endüstri, sosyal hayat ve askeri alanlarda bu yöntem yoğun bir şekilde kullanılmaktadır. Ayrıca SG teknolojilerinde kullanılan nesneler sanal olduğundan dolayı atık malzeme üretmemeleri, nesnelerin kolay bir şekilde ve hammadde tüketmeden üretilmesi ve çoğaltılarak hızlı bir şekilde dağıtılabiliyor olması teknolojinin ekonomik ve çevreci olduğunun apaçık göstergesidir. Dini ve Mura yaptıkları araştırmalarda birçok arttırılmış ve sanal gerçeklik uygulamasını incelemiştir [1]. Dini ve Mura'ya göre arttırılmış gerçeklik teknolojilerinin kullanıcıya süreçlerle ilgili anlık bilgileri gerçek ortamla birlikte verebiliyor olması hayat boyu mühendislik hizmetleri için önemli bir araç olduğunu göstermektedir [1]. Özellikle havacıllk ve tıp gibi alanlarda çok fazla uygulama örneği olan bu teknolojiler endüstriyel alanlarda da kullanılmaktadır. Quandt ve ark. göre endüstriyel alanlarda uygulama geliştirmek diğer alanlara nispeten daha zordur çünkü endüstride iş akışları, zorlu ortamlar, belirli kalite standartları ve ergonomik şartlar uygulama geliştirme süreçlerini zorlaştırmaktadır [2]. Bu zorluklara rağmen endüstriyel, alanda AG'nin gerek maliyetinin düşük olması gerekse donanım ve yazılımlarının kolay erişilebilir olması hasebiyle kullanımı her geçen gün artmaktadır.

Ulusal Yenilenebilir Enerji Laboratuvarında yapılan çalışmalarda rüzgâr girdaplarının davranışlarını incelemek için hazırlanan CFD (Computational Fluid Dynamics) verileri bir SG ortamında sergilenmiştir. Berg ve Vance'e göre bilim adamları oluşan girdapların davranışlarını daha iyi anlayabilmeleri için etkileşimli SG simülasyonlarını kullanmaları gerekir [3]. Böylece bilim adamları ve tasarımcılar daha iyi bir tasarım ortaya koyabilirler. Laboratuvarda gerçekleştirilen başka çalışmalarda malzemelerin de içyapılarını incelemek için SG teknolojisi kullanılmıştır. Berg ve Vance bu verilerin gerçek hayatta bir temsili olmadığı için SG ortamında verilerin zengin bir içerikle temsil edilmesi masaüstü bilgisayarların iki boyutlu ekranlarındaki incelemelere göre daha verimli olduğunu ileri sürmektedir [3]. Berg ve Vance'e göre görselleştirme, bilimsel araştırma süreçleri için destekleyici niteliktedir [3]. John Deere'deki mühendisler CFD verilerini incelemek amacıyla SG kullanmaktadır. Berg ve Vance yaptıkları çalışma ve röportajlardan elde ettikleri verilerle John Deere'de yürütülen çalışmalar gibi büyük verileri içeren incelemelerde SG kullanmak kritik süreçlerde tasarımcıların daha doğru ve hızlı bir şekilde karar vermelerini sağlamaktadır [3].

Autodesk firması CFD verilerinin SG ortamına nasıl aktarılacağı ve CFD verilerinin SG ortamında deneyimlenmesinin kullanıcılara katkılarını gerçekleştirdiği toplantıda sunmuştur [4]. Autodesk hazırladığı sunumunda dijital prototipleme ve simülasyonlar hazırlamanın çevreye olan *Corresponding author: Address: Faculty of Engineering, Department of Civil Engineering Sakarya University, 54187, Sakarya TURKEY. E-mail address: caglar@ sakarya.edu.tr, Phone: +902642955752 Fax: +902642955601 
katkılarının yanı sıra SG teknolojisinin ürün pazarlamadan ziyade bir tasarımda kritik karar alma öğesi olduğunu belirtmiştir. SG teknolojisi günümüzde CFD sunumları için sorunsuz olarak kullanılabilecek bir araçtır [4].

Bina tasarımlarında ısıl analizler binanın yaşam konforu hakkında önemli bilgiler içermektedir. Yokoi ve ark. binalardaki ısı dağılımının sonlu elemanlar yöntemi ile hazırlanmış üç boyutlu CFD modelini AG ortamına aktararak incelemişler [5]. Yokoi ve ark. göre 1sı dağılımını SG ortamında incelemek hem zaman alıcı hem de zahmetli bir hazırlık evresi gerektirmekte olduğu için verileri AG ortamında incelemek zaman ve çaba açısından daha verimli olmaktadır [5]. Bu uygulama bir işaretçiyi referans alarak CFD verilerini gerçek ortam görüntüsünün üzerine kaplamaktadır. Bu yöntemle tasarımcılar CFD verilerinin içinde dolaşarak gerçek zamanlı olarak verileri inceleme imkânı bulmaktadır. Yokio ve ark. göre bu sayede tasarımdaki karar alma süreçleri kısaltılarak zaman daha verimli kullanılmaktadır [5].

AG uygulamaları üretim planlama amacıyla da kullanılabilmektedir. Pentenrieder yaptığı çalışmalarda Roivis arttırılmış gerçeklik uygulamasıyla fabrika içinde engelleyici kenar analizi, konsept planlama, atölye planlama gibi görevleri başarıyla yerine getirmiştir [6]. Bu çalışmalara benzer olarak Kofoğlu ve ark. geliştirdikleri montaj uygulamasında karma gerçeklik kullanarak kullanıcıların birleştirilen parçaları üç boyutlu olarak inceleyebilmesini sağladılar [7]. Herr ve ark. geliştirdikleri arttırılmış gerçeklik uygulamasıyla fabrika içerisindeki makinelerin yerleşimini verimli bir şekilde tespit ederek üç boyutlu olarak görüntülemişlerdir [8]. Herr ve ark. göre arttırılmış gerçeklik uygulamaları gerçek hayatla sürekli iletişim halinde olduğu için karar almak kullanıcılar için daha kolaydır [8]. Mourtzis ve ark. bakım onarım görevlerini uzaktan yardımla yerine getirebilmek için bulut tabanlı bir arttırılmış gerçeklik uygulaması geliştirmişıler [9]. Bu uygulama ile destek ekibi bakım onarım personeline gerekli talimatları sanal ortamda aktararak yardımcı olmaktadır. Onarım faaliyetleri bir bulut ortamında depolanarak paydaşlar arasında her an erişilebilir hale getirilmektedir. Bakım personeli ihtiyaç olduğu zaman bu verilere erişerek gerekli arttırılmış gerçeklik sahnesini kullanarak arızaları giderebilmektedir. Mourtzis ve ark. göre bu arttırılmış gerçeklik uygulamasıyla bakım ve onarım için harcanacak zaman ve maliyetler önemli oranlarda azaltılmaktadır [9]. Bordegoni ve ark. uzaktan bakım desteği vermek üzere benzer bir AG uygulaması geliştirmişler. Herhangi bir arıza durumunda arızanın tespiti için tecrübesiz operatör önce geliştirilen uygulamayla arızalı bölgenin resmini tecrübeli operatöre göndermektedir [10]. Tecrübeli operatör bakım desteği için gerekli talimatları resim üzerine ekleyip sisteme yüklemek suretiyle diğer operatöre iletmektedir. Bakım talimatları AG ile arızalı bölge üzerinde gösterilmektedir. Böylece operatör herhangi bir bakım kılavuzu kullanmadan arızayı giderebilmektedir. Bu uygulamayı durum çalışmasıyla test etmek amaciyla bir otomobilin arızasının giderilmesi için tecrübeli bir operatörün vasıfsız birine geliştirilen uygulamayı kullanarak yardımcı olması incelenmiş ve başarılı sonuçlar alınmıştır. Bordegoni ve ark. göre geliştirilen uygulama şirketlerin bakım maliyetlerini; ulaşım, eğitim ve hızlı müdahale açısından düşürmektedir [10].

Iowa State Üniversitesindeki Sanal Gerçeklik Uygulamaları Merkezi araştırma ekibi sıvı akış özelliklerini sanal gerçeklik teknolojisi ile incelemek amacıyla VE-Suite adlı yazılım paketini geliştirdiler [11]. Yapılan çalışmalarda ParaView programında görselliğini arttırılan CFD analiz sahneleri SG ortamına aktarılmıştır. Böylece kullanıcılara CFD analiz verilerini sanal gerçeklik 
ortamında sunarak verilerin daha hızlı ve daha kolay bir şekilde anlaşılmasını ve CFD analizlerinde uzman olmayan tasarım mühendislerinin analiz sonuçlarını değerlendirerek hızlı tasarımsal kararlar alabilmesi sağlanmıştır. Fu ve ark. göre disiplinler arasındaki iletişim kurma amacıyla CFD verilerini sunma yönünden sıradan bilgisayar ile karşılaştırıldığında SG ortamı çok daha ikna edicidir [11].

Yap ve ark. makine imalat ve yapı inşaatı sektörlerinde kalifiye kaynakçı ihtiyacını karşılamanın zorluklarını dikkate alarak kalifiye kaynakçı eğitimine yönelik sanal gerçeklik uygulaması geliştirmişlerdir [12]. Bu uygulamada kullanıcı sanal gözlük ve kalem yerine kaynak torcu bağlanmış bir stylus kullanarak MAG kaynağı simülatörünü kullanmaktadır. Uygulama kullanıcının hareketlerine göre simüle olup kullanıcıya sanal bir kaynaklama deneyimi sunmaktadır. Yap ve ark. göre, bu ve benzeri uygulamalarla modern kaynak eğitimlerinin maliyetlerini azaltmak mümkündür [12].

Kofoğlu ve ark. göre arttırılmış gerçeklik teknolojisi hızlı bir şekilde eğitime kazandırılması gereken önemli bir yardımcı materyaldir [13]. Temel, orta ve ileri eğitimlerin yanı sıra mesleki ve mühendislik eğitimlerinde de AG ve SG uygulamaları yardımcı birer materyal olmaktadır. Huerta ve ark. arttırılmış gerçeklik teknolojisini kullanarak mesleki ve mühendislik eğitimlerinde kullanılmak üzere uygulama geliştirmişler [14]. Bu uygulamada teknik resim okuma ve tolerans verme kuralları etkili bir şekilde anlatılmaktadır. Çalışmalar kapsamında 20 kişilik bir katılımcı ile gerçekleştirilen eğitimlerde geliştirdikleri AG uygulamalarının eğitimlerde yardımcı materyal olarak öğrenmeye katkı sağladığını kanıtladılar [15]. Ayrıca Arslan ve ark. biyoloji ve veterinerlik eğitiminde kullanılmak üzere geliştirdikleri arttırılmış gerçeklik uygulaması ile bir kurbağa modelini ele alarak kurbağanın kas, iskelet ve organlarını incelemenin öğrenmeye katkılarını araştırmışlar [16]. Arslan ve ark. göre geliştirilen uygulama ile öğrenme performansı artarken eğitimlerde kullanılacak denek hayvan sayısının azalması beklenmektedir [16].

Kömürle çalışan güç santrallerinde stajyerlerin santralde gerçekleşen olayları doğru bir şekilde anlamaları büyük öneme sahiptir. Moreland ve ark. güç santrallerinde güç üretmek amaciyla kullanılan ocakların içindeki olayları AG teknolojisi ile görüntüleyerek katılımcıların ocaklardaki akışkan hareketlerini daha iyi anlamalarını sağlamıştır [17].

Birçok alanda kolaylıkla kullanılabilen bu görselleştirme teknolojilerinin birbirlerine göre artıları ve eksileri vardır. SG uygulamaları bireysel kullanımlarda kullanıcıyı gerçek dünyadan soyutlayarak sanal dünyaya götürebilse de bu yöntem aynı anda birden fazla kullanıcının aynı görüntüyü görmesine müsaade etmemektedir. AG yönteminde ise kullanıcılar uygulama üzerinde aynı görüntüyü görebilmektedir fakat görüntü iki boyutlu bir ekran ile sınırlanmaktadır. Öte yandan XR uygulamaları kullanabilmek için pahalı XR gözlüklerine ihtiyaç vardır. Sunulan çalışmada hem AG hem de XR yönteminin kullanıldığ 1 bir mobil uygulama geliştirilmesi ve bu uygulamanın akıllı telefonlarla kullanılabilmesi için düşük maliyetli bir gözlük tasarlanması irdelenecektir.

\section{Materyal ve Yöntem}

AG, SG ve XR teknolojileri eğitim, endüstri ve inşaat, askeriye ve tıp başta olmak üzere birçok alanda siklıkla kullanılmaktadır. Bu teknolojilerle birlikte bu teknolojilerin donanımları da bir 
ihtiyaç haline gelmiştir. Hali hazırda olan giyilebilir; eldivenler, gözlükler, başlıklar ve bilekliklerin yanı sıra yapay zekâ ve görüntü işleme teknolojileri ile desteklenen kızıl ötesi sensör ve/veya manyetik sensörlü cihazlar, konum, hız ve ivme sensörleri ile donatılmış konsollar SG teknolojileri ile kullanılmaktadır. Bu çalışma kapsamında bir mobil uygulama içerisinde hem AG hem de XR yönteminin birlikte kullanılabilmesi için bir yöntem geliştirilerek bu yönteme uygun gözlük tasarımı ve imalatı yapıldı (Şekil 1).

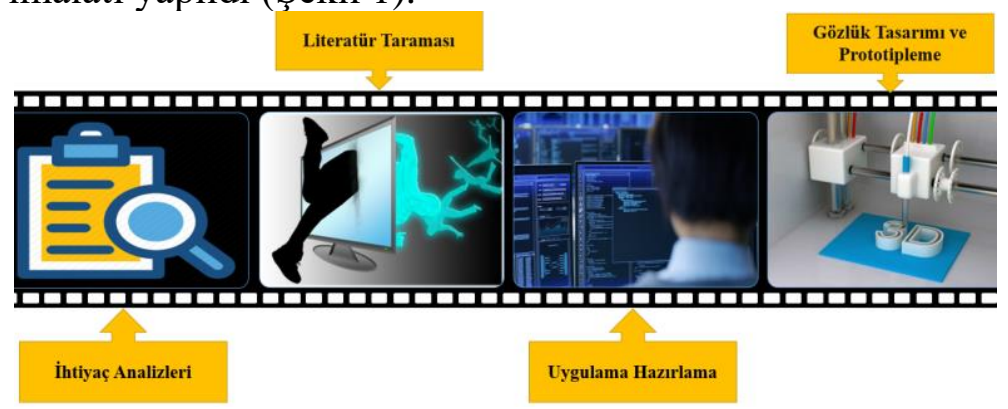

Şekil 1. Uygulama ve gözlük geliştirme aşamaları

\subsection{Karma Gerçeklik Uygulaması Geliştirilmesi}

Çalışma kapsamında arttırılmış gerçeklik uygulaması geliştirilirken sıklıkla tercih edilen Unity3D programı ve Google ARCore kütüphanesi kullanıldı. Uygulama hazırlamaya başlarken öncelikle gerek uygulama gerekse gözlük tasarımı için kullanım gereksinimleri ve kısıtları belirlendi. Bunlar özetlenecek olursa;

- $\quad$ Uygulamada kullanılacak nesneler gerçek cisimlerle ölçekli olmalıdır.

- $\quad$ Uygulamanın menüsü kullanışlı olmalıdır.

- $\quad$ Hazırlanacak gözlük ergonomik ve ekonomik olmalıdır.

- Kullanıcı uygulama ile sürekli etkileşim halinde olabilmelidir.

- Hazırlanacak donanım hafif ve estetik olmalıdır.

- $\quad$ İki teknoloji arasındaki geçişlerde zaman ve nesnelerin ölçek kaybı minimize edilmelidir.

Arttırılmış gerçeklik uygulaması geliştirilirken öncelikle ihtiyaçlar belirlendi, ardından literatür taraması yapıldı, ön uygulama hazırland1, gözlük prototipi hazırlandı ve gözlük üç boyutlu yazıcı ile imal edildi. Geliştirilen ön uygulama üretilen karma gerçeklik gözlüğü ile test edildi.

Çalışmanın bu aşamasında uygulamada gösterilecek olan katı modeller ve uygulamanın menüsünde kullanılacak tuşlar hazırlandı. Mobil uygulama geliştirmek için Unity3D programı ve AG özelliği için Google ARCore kütüphanesi kullanıldı. Unity3D programında katı modeller, programın kendi içinde tasarlanabileceği gibi hazır olarak dışarıdan da temin edilebilir. Fakat Unity3D sadece obj ve fbx uzantılı dosyaları desteklemektedir. Bu nedenle uygulamaya dışarıdan eklenecek olan katı modeller Inventor programı yardımıyla obj dosya formatına dönüştürüldü.

Şekil 2'de gösterilen uygulama arayüzünde yer alan tuşlara, uygulamayı sonlandırma, menüyü kapatma, XR moda geçme, çatıyı açma-kapatma, 1:1 ölçekleme ve ana menüye dönme işlevleri tanımlanmıştır. Böylece uygulamanın kullanımı kolaylaştırılmıştır. Ayrıca sanal nesneleri parmak yardımıyla yönlendirebilmek için uygulamaya döndürme, büyütme, taşıma ve tıklama özellikleri eklenmiştir. Son olarak uygulama Unity3D üzerinde test edildikten sonra uygulama APK 
formatında derlenerek OnePlus 5T cihazıyla da test edilmiştir.

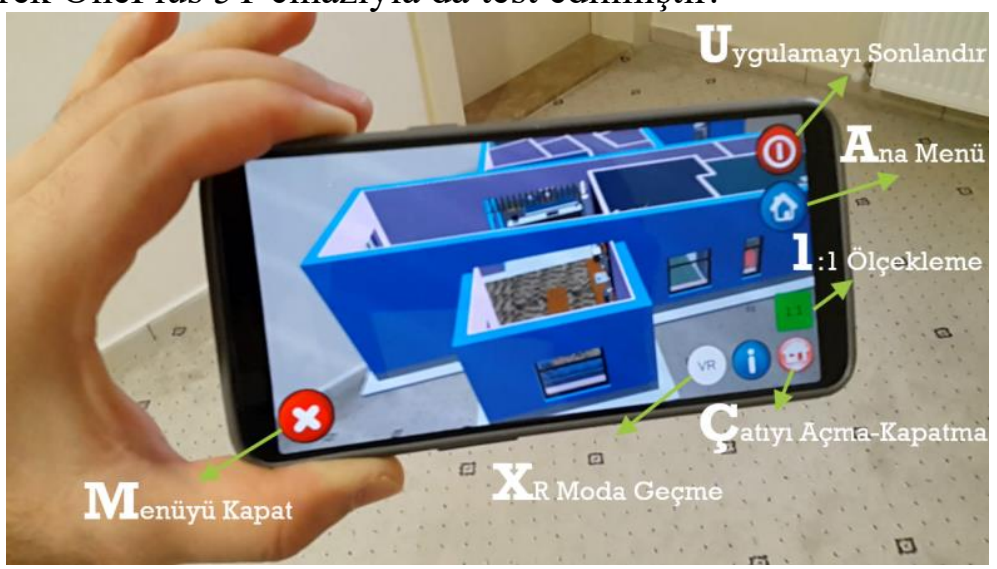

Şekil 2. Uygulamanın AG incelenmesi

Uygulamanın test edilebilmesi için mercek ve karton kullanılarak gözlük maketi hazırlandı. Hazırlanan maket gözlüğün yapısal özelliklerine bağlı olarak Tablo 1'de verilen kamera yerleşim planı deneysel olarak tespit edildi ve uygulamada kullanıldı. Burada $25 \mathrm{~mm}$ çaplı cam mercekler kullanıld1.

Tablo 1. Uygulamada kullanılacak kameraların ekrandaki yerleşim ve boyutsal özellikleri

\begin{tabular}{llllll}
\hline \multirow{2}{*}{ AG Kamera } & \multirow{2}{*}{ Merkezi Kamera } & X & 0 & Y & 0 \\
\cline { 3 - 6 } & \multirow{2}{*}{ Sağ Kamera } & W & 1 & H & 1 \\
\hline \multirow{3}{*}{ MR Kamera } & X & 0,53 & Y & 0,25 \\
\cline { 2 - 6 } & \multirow{2}{*}{ Sol Kamera } & W & 0,4 & H & 0,4 \\
\cline { 2 - 6 } & & X & 0,09 & Y & 0,25 \\
\cline { 2 - 6 } & & W & 0,4 & H & 0,4 \\
\hline
\end{tabular}

Karma gerçeklik uygulamasının performansı ve standart gözlüklerle uygunluğu incelendi. Burada geliştirilen uygulama mevcut sanal gerçeklik gözlükleri ile de incelenerek uygun olduğu gösterilmiştir. Şekil 3 ve Şekil 4'de karma gerçeklik uygulaması ve piyasadan temin edilen sanal gerçeklik gözlüğü ile uygulamanın kullanımı görülmektedir.

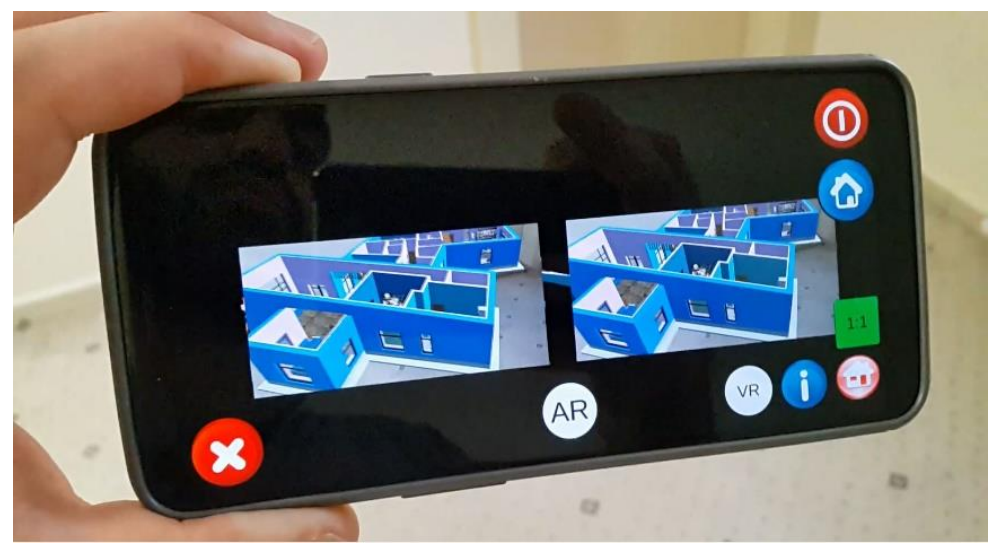

Şekil 3. Uygulamanın karma gerçeklikle incelenmesi 


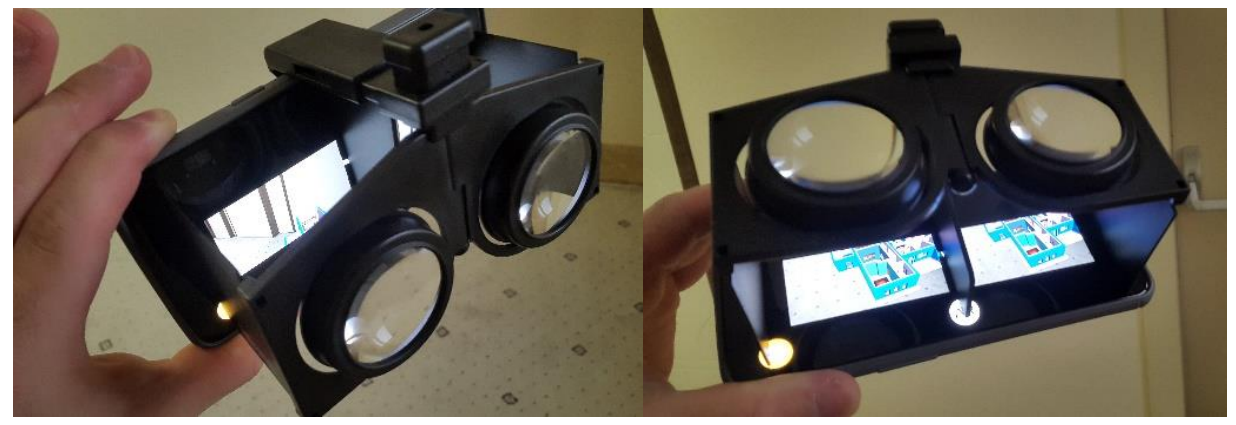

Şekil 4. Basit yapılı bir sanal gerçeklik gözlüğü ile karma gerçeklik uygulamasının yapısal uyumluluğunun incelenmesi

Şekil 5'de görüldüğü üzere uygulama beklenilenin ötesinde bir gerçeklik etkisi sunmaktadır.

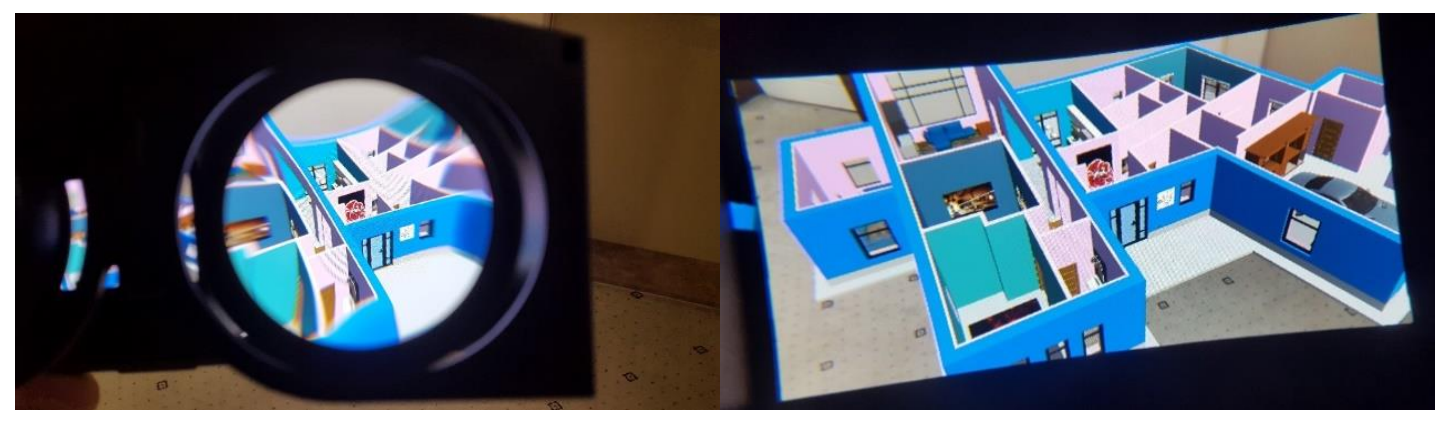

Şekil 5. Ekranın merceğin odağına getirilmesi ve Karma gerçeklik uygulamasının gerçeklik etkisinin incelenmesi

Yukarıda tartışılan yöntem ile makine mühendisliği ve mesleki eğitime yönelik olarak toleranslar üzerine arttırılmış gerçeklik uygulaması geliştirilmiştir (Kofoğlu, 2019). Bu çalışmada ele alınan uygulama hem arttırılmış hem de karma gerçeklik teknolojileri birleştirilerek tek bir uygulama içinde birleştirilmiştir (Şekil 6).

\subsection{Karma Gerçeklik Gözlüğ̈̈ Tasarlanması ve Üretilmesi}

Karma gerçeklik gözlüğü tasarlanırken mobil cihazın ekranı kullanılacak merceklerin odak noktasına denk gelmesi gerekmektedir. Mercekler arasındaki mesafe mobil cihazın ekranının uzun kenarının yarısı kadar olmalıdır. Arttırılmış gerçekliğin kullanılabilmesi için gözlüğün arkasında kamera boşluğu bırakılmalıdır.

Uygulama geliştirme aşaması tamamlandıktan sonra maket gözlük üzerinden alınan ölçüler katı modelleme programına aktarıldı. Gözlük tasarımı üç boyutlu üretim yöntemine uygun ve tek parça olarak üretilecek biçimde yeniden düzenlendi (Şekil 7). 


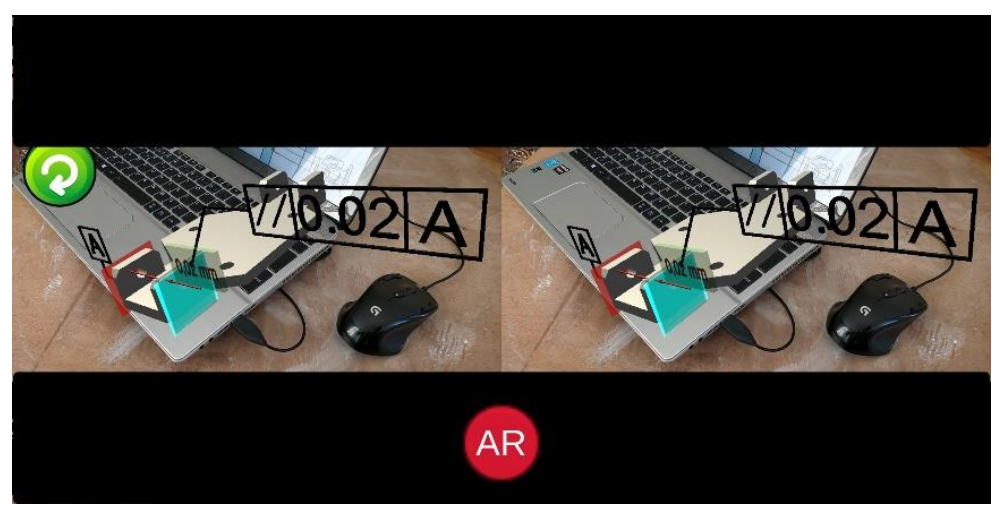

Şekil 6. Mesleki eğitime yönelik uygulama tasarlanması
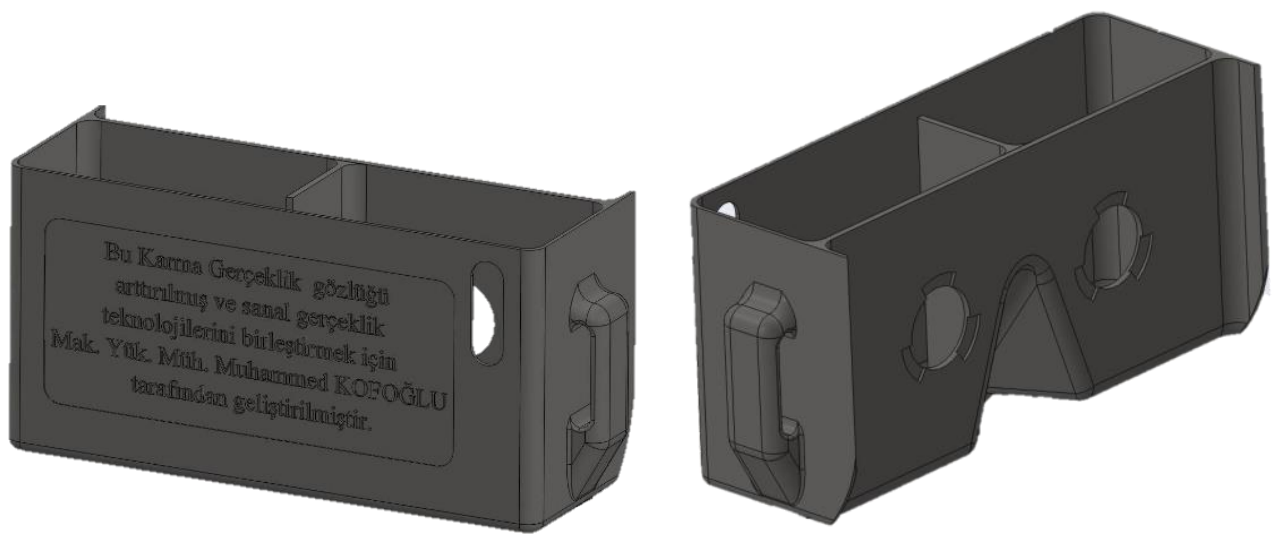

Şekil 7. Karma gerçeklik gözlüğünün tasarlanması

Tasarımı tamamlanan gözlük amatör bir üç boyutlu yazıcıdan 400 mikron çaplı nozul kullanılarak 200 mikron katman kalınlı̆̆ ile yaklaşık 10 saatte üretildi. Yazıcıdan elde edilen modelin çapakları temizlendi, mercekleri yerleştirildi ve kafa bandı takıldı (Şekil 8). Nihai şeklini alan karma gerçeklik gözlüğ̈̈ One Plus 5T mobil cihazı ile test edildi.

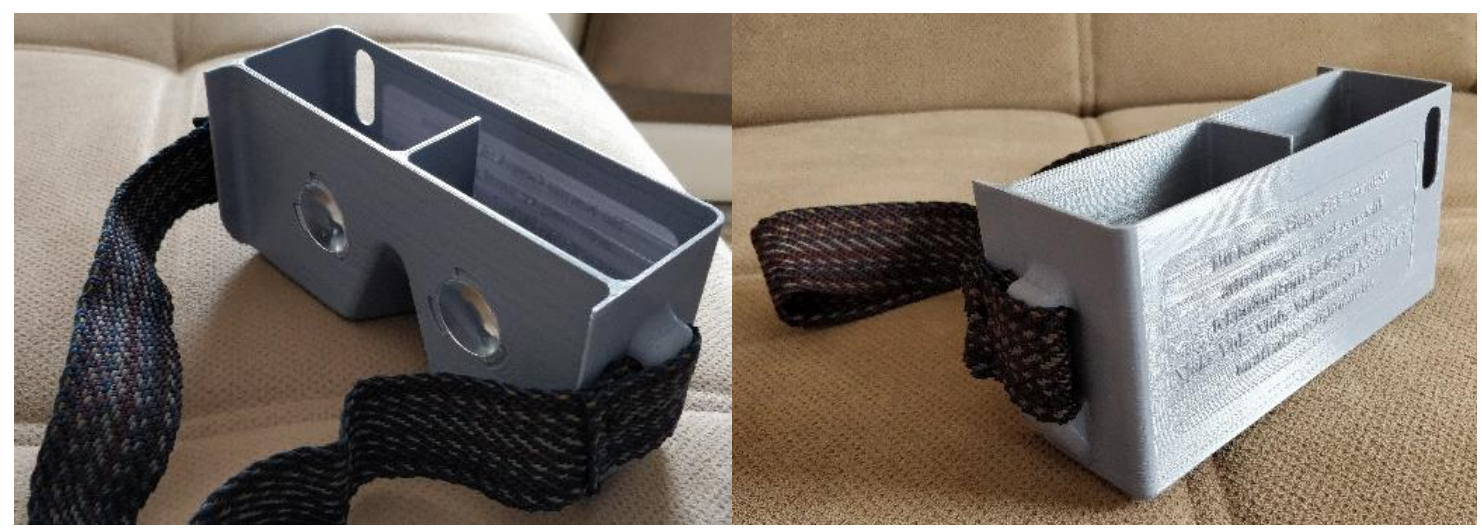

Şekil 8. Karma gerçeklik gözlüğü için prototip üretilmesi 


\section{Değerlendirme ve Sonuçlar}

Yapılan çalışmalarda bir uygulama içinde hem arttırılmış hem de karma gerçeklik tekniği kullanılarak bir kişi uygulamayı kullanırken (karma gerçeklik seçeneği) iki elinin serbest kalmasıyla hem kullanım kolaylığı hem de uygulamayı yönetmek için harici kontrolcüler kullanma imkânı sağlanmıştır. Aynı uygulamanın birden çok kullanıcı tarafından kullanılabilmesi için de uygulamanın arttırılmış gerçeklik seçeneğiyle birden çok kullanıcının aynı anda uygulama ile etkileşmesine olanak sağlanmıştır. Böylece mesleki eğitime yönelik geliştirilen uygulamalar hem bireysel hem de toplu olarak çalışmaya uygun hale gelmektedir.

Geliştirilen karma gerçeklik gözlüğü ile mekanik, 1sıl, akış, manyetik,... birçok analiz sonuçları gerçek dünyada araştırmacılar tarafından incelenebilir. Böylece bu analizler hakkında daha fazla bilgi sahibi olunabilir.

İleriki çalışmalarda, uygulama yapay zekâ ile desteklenerek el hareketlerine duyarlı hale getirilebilir ve bu sayede kullanıcı gerçek dünyadaki nesnelere müdahale edebildiği gibi sanal nesnelere de müdahale edebilir. Uygulamanın içerisindeki sanal bir nesnenin başlica konumsal ve dönel hareketi ve ölçeklendirme kabiliyeti kullanıcının sanal deneyimini çok ileri taşıyacaktır. Ayrıca daha ileri uygulamalarda kullanıcı karma gerçeklik kullanarak serbest elle tasarım yapma ve mevcut bir tasarım üzerinde değişiklikler yapma olanağı sağlanabilir.

\section{Kaynaklar}

[1] Dini, G., \& Dalle Mura, M. (2015). Application of augmented reality techniques in throughlife engineering services. Procedia Cirp, 38, 14-23.

[2] Quandt, M., Knoke, B., Gorldt, C., Freitag, M., Thoben, K. D. 2018. General Requirements for Industrial Augmented Reality Applications. Procedia CIRP, 72: 1130-1135.

[3] Berg, L. P., Vance, J. M. 2017. Industry use of virtual reality in product design and manufacturing: a survey. Virtual reality, 21(1): 1-17.

[4] Anonim, 2017. CFD Meets VR Lab. https://www.autodesk.com/autodeskuniversity/class/CFD-Meets-VR-Lab-2017\#handout (Erişim Tarihi: 16.01.2019)

[5] Yokoi, K., Fukuda, T., Yabuki, N., Motamedi, A. 2016. Integrating CFD and AR for indoor thermal environmental design feedback. 2016, Proceedings of the 11th ISAIA, Miyagi

[6] Pentenrieder, K. (2009). Augmented reality based factory planning (Doctoral dissertation, Technische Universität München).

[7] Kofoğlu, M., Dargut, C., Arslan, R., Kuş, A. 2018. 3D Modellerde Poligon Yapısının Artırılmış Gerçeklik Uygulamaları Üzerindeki Etkileri. 9 th International Automotive Technologies Congress, OTEKON 2018, pp. 1844, Bursa

[8] Herr, D., Reinhardt, J., Krüger, R., Reina, G., \& Ertl, T. (2017). Immersive Visual Analytics for Modular Factory Layout Planning. In Workshop on Immersive Analytics of IEEE VIS.

[9] D. Mourtzis, V. Zogopoulosa, E. Vlachoua (2017). "Augmented reality application to support remote maintenance as a service in the Robotics industry" ,The 50th CIRP Conference on Manufacturing Systems, Procedia CIRP 63 ( 2017 ) 46 - 51, 2212-8271 C 2017, The Authors. doi: 10.1016/j.procir.2017.03.154

[10] Bordegoni, M., Ferrise, F., Carrabba, E., Di Donato, M., Fiorentino, M., Uva, A. E. 2014. 
An application based on Augmented Reality and mobile technology to support remote maintenance. Conference and Exhibition of the European Association of Virtual and Augmented Reality, 1(1): 131-135.

[11] Fu, D., Wu, B., Chen, G., Moreland, J., Tian, F., Hu, Y., Zhou, C. Q. 2010. Virtual reality visualization of CFD simulation for iron/steelmaking processes. In 2010 14th International Heat Transfer Conference (pp. 761-768). American Society of Mechanical Engineers.

[12] Yap, H. J., Taha, Z., Choo, H. K., \& Kok, C. K. (2014). Virtual Reality-based Training System for Metal Active Gas Welding. In The Thousand Faces of Virtual Reality. IntechOpen.

[13] Kofoğlu, M., Kuş, A., Emreli, D., Arslan, R., Ünver, E., \& Kagioglou, M. (2019). Mühendislik eğitiminde geometrik toleransların öğretimine yönelik artırılmış gerçeklik uygulaması geliştirilmesi. Uludağ Üniversitesi Mühendislik Fakültesi Dergisi, 173-183.

[14] Huerta, O.; Kus, A.; Unver, E.; Arslan, R.; Dawood, M.; Kofoğlu, M. and Ivanov, V. (2019). A Design-based Approach to Enhancing Technical Drawing Skills in Design and Engineering Education using VR and AR Tools.In Proceedings of the 14th International Joint Conference on Computer Vision, Imaging and Computer Graphics Theory and Applications - Volume 3: IVAPP, ISBN 978-989-758-354-4, pages 306-313. DOI: 10.5220/0007566003060313

[15] Emreli, D., Kofoğlu, M., Kuş, A., Arslan, R., Unver, E. 2019. Teknik Resim Eğitimi İçin Geliştirilen Sanal Gerçeklik Öğretim Materyalinin Öğrencilerin Kavramsal ve Bilişsel Öğrenme Düzeylerine Etkisinin İncelenmesi. Uluslararası Fen, Matematik, Girişimcilik ve Teknoloji Eğitimi Kongresi, FMGT 2019, İzmir

[16] ARSLAN, R., KOFOĞLU, M., \& DARGUT, C. (2020). Development of Augmented Reality Application for Biology Education. Journal of Turkish Science Education, 17(1), 62-72.

[17] Moreland, J., Wang, J., Liu, Y., Li, F., Shen, L., Wu, B., Zhou, C. 2013. Integration of augmented reality with computational fluid dynamics for power plant training. In Proceedings of the International Conference on Modeling, Simulation and Visualization Methods (MSV) (p. 1). The Steering Committee of The World Congress in Computer Science, Computer Engineering and Applied Computing (WorldComp). 